\title{
Novel effect of medicinal plants on diabetes mellitus
}

Keywords: diabetes mellitus, hyperglycemic, $\alpha$-glucosidase, $\beta$ cells, insulin

Abbreviations: DM, diabetes mellitus; $\mathrm{HbA}_{1} \mathrm{c}$, haemoglobin $\mathrm{A}_{1} \mathrm{c}$ level; IGF, impaired glucose tolerance; IFG, impaired fasting glucose; AGEs, advanced glycation end products; DPP-IV, dipeptidyl peptidase-IV

\section{Introduction}

Diabetes mellitus (DM) is a chronic non-communicable disease and 422 million people had DM in 2014. ${ }^{1}$ There is increasing in number of DM and about 642 million people will be expected to suffer from DM in $2040 .^{2}$ It can be diagnosed by high blood glucose level (hyperglycemia), increased haemoglobin $\mathrm{A}_{1} \mathrm{c}$ level $\left(\mathrm{HbA}_{1} \mathrm{c}\right)$, fatigue, weight loss, polydipsia, polyuria Figure 1. There are Type 1 diabetes (insulin-dependent, juvenile or childhood-onset), type 2 diabetes (non-insulin-dependent, or adult-onset), gestational diabetes which occurs during pregnancy, impaired glucose tolerance (IGT) and impaired fasting glucose (IFG) which are intermediate conditions between normal and diabetes and unclassified diabetes ${ }^{3}$. So, novel effects of medicinal plants are needed to discover for new therapeutic agents for DM Figure 2.

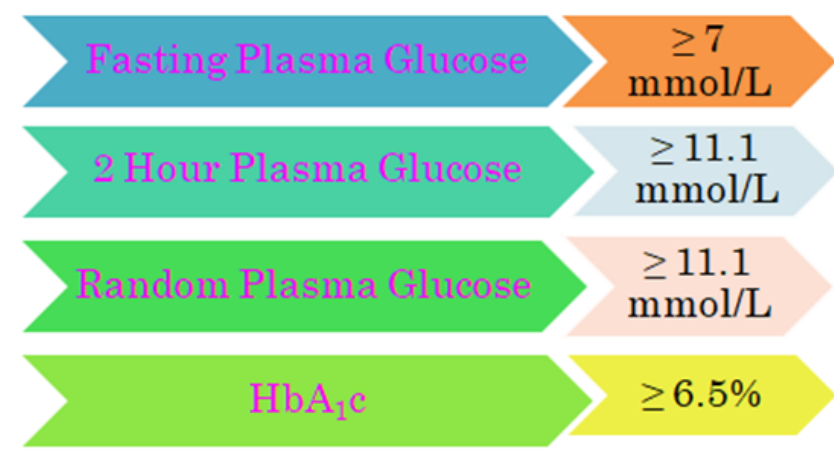

Figure I Modified diagnostic criteria for DM. ${ }^{3}$

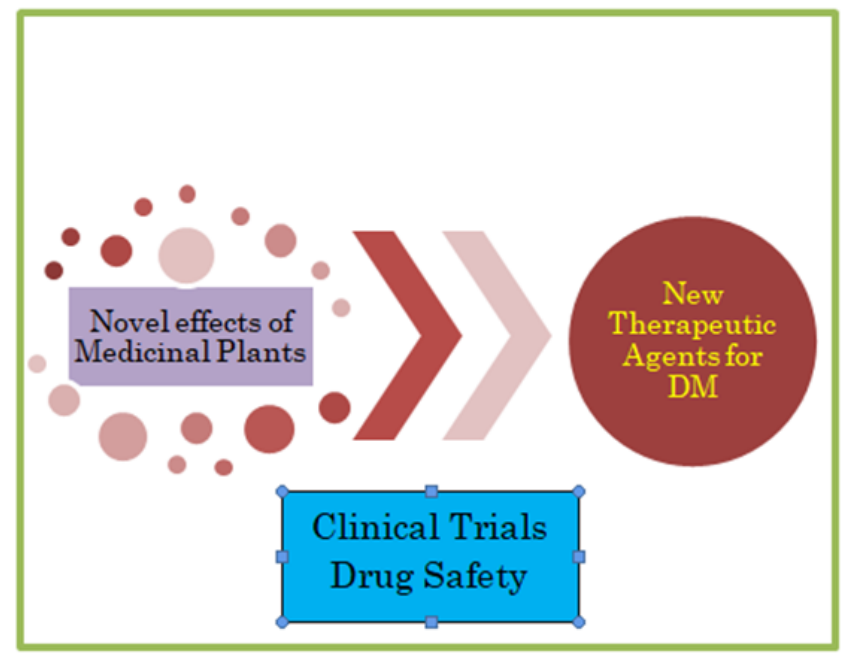

Figure 2 Prospect of new therapeutic agents for DM.
Volume 7 Issue 2 - 2020

\author{
Myat Thu Thu Win \\ Faculty of Medicine,AIMST University, Malaysia
}

Correspondence: Myat Thu Thu Win, Senior Lecturer, Faculty of Medicine, AIMST University, Malaysia, Emailmthuhusan@gmail.com

Received: June 09, 2020 | Published: June 30, 2020

\section{Sources and effects of medicinal plants}

Australian medicinal plants such as Petalostigmapubescens, Petalostigma banksia which have $\alpha$-amylase inhibition, $\alpha$-glucosidase inhibition and glucose-induced fluorescent advanced glycation end products (AGEs) inhibition but further study is needed for using as treatment of DM. ${ }^{4}$ Sudanese medicinal plants like Acacia nilotica, Ziziphus spina-christi, Geigeriaalata showed that they have potent antioxidant, anti-hyperlipidemic and $\alpha$-glucosidase inhibition properties so it will be expected to use as plant derived antidiabetic agents after animal and clinical studies. ${ }^{5}$ A very valuable medicinal plant Kothalahimbutu also known as Salacia reticulata seen in Sri Lanka and South India have multiple effects like antioxidant, hepatoprotectant effects and inducing effects on aldose reductase, peroxisomal proliferator-activated receptor- $\alpha$, glucose transporter-4 mediated glucose uptake. In addition to this, Salacia oblonga extracts significantly lower the postprandial glucose curve in type 2 diabetic patients. ${ }^{6}$ Likewise, Berries extract and its compounds have beneficial effects on DM and metabolic diseases by improving insulin resistance and reduce inflammation to regulate the blood glucose effectively. The hyperglycemic control effect is similar to metformin drug used in type-2 DM patients.?

Medicinal plants like Momordicacharantia which fruits (bitter gourd) have critical role in stimulating isolated pancreatic $\beta$ cells to secrete insulin in obese hyperglycemic mice and to renew $\beta$ cells and to recover damaged $\beta$ cells in Streptozocin induced diabetic rats. It was suggested that the novel effect of this extract may reduce not only hepatic glycogenesis but also increase glucose utilization in periphery. ${ }^{8}$ It can inhibit $\alpha$-amylase and $\alpha$-glucosidase in vitro and reduce blood glucose level in Streptozotocin-induced diabetic rats when they were given orally. These two enzymes may play a role in carbohydrates metabolism and cause postprandial increase glucose level in diabetic patients. ${ }^{9}$ One of the medicinal plants which have beneficial effect on DM is resveratrol. It has many different mechanisms like prevention of abnormal glucose uptake and storage, apoptosis and dysfunction pancreatic $\beta$ cells and improved insulin resistance. ${ }^{10}$ Similarly, traditional plants used in Persian medicine 
(e.g. Bambusaarundinasi, Coriandrumsativum, Myrtuscommunis) have antidiabetic effects by increasing insulin, liver glycogen, inhibiting deteriorative changes in $\beta$ cells and $\alpha$-glucosidase enzyme inhibition. So, these plants may be useful for prevention and treatment of diabetes and complications. ${ }^{11}$ In addition to this, researchers are trying to explore the anti-hyperglycemic effects of different medicinal plants is increasing because of lower costs and lesser side effects of medicinal plants. Recent study showed that plant origin quercetin and coumarin have inhibitory effects on dipeptidyl peptidase-IV (DPPIV) enzyme which increases endogenous incretins activity results in insulin stimulating effect and reduce blood sugar level. Both of them have not only anti-hyperglycemic action but also antioxidant action. ${ }^{12}$

\section{Conclusion}

In spite of many medicinal plants have antidiabetic properties by acting different mode of mechanisms, the development of novel therapeutic agents for DM is still awaiting. Further studies are required for safety issues and clinical trials are essential for use as treatment and prevention for DM in human.

\section{Acknowledgments}

None.

\section{Conflicts of interest}

The author declares that there is no conflict of interest.

\section{Funding}

None.

\section{References}

1. World Health Organisation. Diabetes. 2020.

2. Ogurtsova K, da Rocha Fernandes JD, Huang Y, et al. IDF Diabetes Atlas: Global estimates for the prevalence of diabetes for 2015 and 2040 Diabetes Res Clin Pract. 2017;128:40-50.
3. International Diabetes Federation. IDF Diabetes Atlas, $9^{\text {th }}$ ed. Brussels, Belgium: International Diabetes Federation. 2019.

4. Deo P, Hewawasam E, Karakoulakis A, et al. In vitro inhibitory activities of selected Australian medicinal plant extracts against protein glycation, angiotensin converting enzyme (ACE) and digestive enzymes linked to type II diabetes. BMC Complement Altern Med. 2016;16(1):435.

5. Elbashir SM, Devkota HP, Wada M, et al. Free radical scavenging, $\alpha$-glucosidase inhibitory and lipase inhibitory activities of eighteen Sudanese medicinal plants. BMC Complement Altern Med. 2018;18(1):282.

6. Win MTT, Soe T. At a glance on Kothala himbutu. International Journal of Diabetes \& Metabolic Disorders. 2019;4(3):1-2.

7. Belwal T, Bisht A, Devkota HP, et al. Phytopharmacology and clinical updates of berberis species against diabetes and other metabolic diseases. Front Pharmacol. 2020;11:41.

8. Jia S, Shen M, Zhang F, et al. Recent advances in Momordicacharantia: functional components and biological activities. Int $J \mathrm{Mol} S \mathrm{Sci}$. 2017;18(12):2555.

9. Poovitha $\mathrm{S}$, Parani M. In vitro and in vivo $\alpha$-amylase and $\alpha$-glucosidase inhibiting activities of the protein extracts from two varieties of bitter gourd (Momordicacharantia L.). BMC Complement Altern Med. 2016;16 Suppl 1(Suppl 1):185

10. Oyenihi OR, Oyenihi AB, Adeyanju AA, et al. Antidiabetic effects of resveratrol: the way forward in its clinical utility. $J$ Diabetes Res. 2016:9737483.

11. Farzaei F, Morovati MR, Farjadmand F, et al. A mechanistic review on medicinal plants used for diabetes mellitus in traditional Persian medicine. J Evid Based Complementary Altern Med. 2017;22(4):944-955.

12. Singh AK, Patel PK, Choudhary K, et al. Quercetin and coumarin inhibit dipeptidyl peptidase-IV and exhibits antioxidant properties: in silico, in vitro, ex vivo. Biomolecules. 2020;10(2):207. 